Artikel Penelitian

\title{
PERSEPSI PERAWAT TENTANG DAMPAK AKREDITASI TERHADAP MUTU PELAYANAN KESEHATAN
}

\author{
CHAIRANUR DARA PHONNA ${ }^{1}$, DEWI RATNA SARI ${ }^{1}$, AMI NURYANTI', DESIMA BORU KARO' \\ 1 Surveyor Keperawatan, Komisi Akreditasi Rumah Sakit (KARS)
}

Email korespondensi: dewi.rs88@gmail.com

Dikirimkan 25 Februari 2021, Diterima 20 Juni 2021

\begin{abstract}
Abstrak
Latar Belakang: Dalam upaya peningkatan mutu pelayanan, rumah sakit wajib melakukan akreditasi secara berkala minimal 4 tahun sekali. Sebagai tenaga profesional yang dominan di sebuah rumah sakit, perawat banyak terlibat dalam kegiatan akreditasi di rumah sakit sehingga persepsi perawat tentang dampak akreditasi terhadap mutu pelayanan kesehatan di rumah sakit menjadi sangat penting karena pelayanan keperawatan adalah suatu bentuk pelayanan profesional yang merupakan bagian integral dari pelayanan kesehatan yang ada di sebuah rumah sakit.
\end{abstract}

Tujuan: Mengeksplorasi persepsi perawat terhadap dampak akreditasi pada mutu pelayanan rumah sakit.

Metode: Penelitian kualitatif dengan desain fenomenologi yang dilakukan dengan Focus Group Discussion (FGD) menggunakan pedoman FGD. Penelitian dilakukan pada bulan Juni tahun 2020, partisipan berjumlah 53 perawat (7 kelompok FGD) di empat rumah sakit. Kriteria inklusi kepala ruang dengan masa jabatan lebih dari lima tahun dan berpendidikan sarjana keperawatan serta aktif sebagai anggota pokja akreditasi. Kriteria eksklusi adalah kepala ruang dengan pendidikan D3 atau Sekolah Perawat Kesehatan (SPK), perawat pelaksana atau ketua tim. Partisipan berasal dari empat rumah sakit, yaitu 1 RS di DKI Jakarta, 2 RS di Sumatera Utara dan 1 RS di Aceh. Hasil rekaman disusun dalam bentuk transkrip dan dilakukan analisis data dengan menentukan kategori dan tema.

Hasil: Secara umum akreditasi memberikan dampak positif dan dampak negatif. Dampak positif meliputi sarana dan prasarana menjadi lebih lengkap; regulasi sesuai standar dan lebih lengkap; peningkatan pengetahuan dan keterampilan staf rumah sakit; sistem pendokumentasian lebih baik; peningkatan mutu pelayanan; melindungi keselamatan pasien dan staf; budaya organisasi menjadi lebih baik. Namun akreditasi juga memiliki dampak negatif berupa dokumentasi lebih banyak; beban kerja meningkat; tidak melibatkan seluruh staf rumah sakit; membutuhkan biaya besar; rumah sakit tidak mampu menyediakan fasilitas dan sarana prasarana sesuai standar; membutuhkan lebih banyak waktu. Akreditasi berdampak positif terhadap mutu pelayanan kesehatan yaitu: pelayanan yang diberikan sesuai standar; peningkatan mutu dan keselamatan pasien; dan kepuasan pasien meningkat.

Kesimpulan: Secara umum perawat mempunyai persepsi bahwa akreditasi mempunyai dampak positif dan negatif, serta dapat mendorong peningkatan mutu pelayanan kesehatan menjadi lebih baik.

Kata kunci: persepsi perawat, dampak akreditasi, mutu pelayanan kesehatan

\section{Latar Belakang}

Undang-Undang Nomor 44 tahun 2009 menyatakan bahwa rumah sakit adalah institusi pelayanan kesehatan yang menyelenggarakan pelayanan kesehatan perorangan secara paripurna yang menyediakan pelayanan rawat inap, rawat jalan, dan gawat darurat ${ }^{1}$. Sebagai suatu institusi pelayanan kesehatan, rumah sakit seharusnya mampu memberikan pelayanan yang bermutu sesuai dengan standar-standar pelayanan kesehatan yang telah ditetapkan dengan mengacu kepada peraturan perundang-undangan, peraturan pemerintah, kolegium profesi maupun peraturan-peraturan lainnya.

Dari hasil penelitian Kusbaryanto mengatakan bahwa peningkatan mutu pelayanan rumah sakit merupakan hal yang sangat penting, karena rumah sakit memberikan pelayanan yang yang berisiko tinggi ${ }^{2}$. Menurut Peraturan Menteri Kesehatan Nomor 12 tahun 2020, salah satu upaya peningkatan mutu pelayanan rumah sakit adalah melalui akreditasi berkala paling sedikit 4 tahun sekali3. Rumah sakit yang periodik melakukan akreditasi dapat mempertahankan mutu pelayanan kesehatannya secara kontinyu 4 .

Akreditasi rumah sakit merupakan sebuah penilaian yang mengacu kepada elemen penilaian dalam standar akreditasi yang pelaksanaannya dimulai dari persiapan, pelaksanaan kegiatan sampai dengan pemenuhan rekomendasi setelah akreditasi. Rangkaian kegiatan tersebut dilalui oleh seluruh staf rumah sakit sehingga memberikan dampak bagi rumah sakit. 
Akreditasi rumah sakit dapat memberikan dampak positif dan dampak negatif5.

Sebagai tenaga profesional terbanyak di sebuah rumah sakit, perawat banyak terlibat dalam kegiatan akreditasi. Oleh karenanya, persepsi perawat tentang dampak akreditasi terhadap mutu pelayanan kesehatan di rumah sakit menjadi sangat penting. Menurut Undang-undang Nomor 38 tahun 2014, pelayanan keperawatan adalah suatu bentuk pelayanan profesional yang merupakan bagian integral dari pelayanan kesehatan di rumah sakit ${ }^{6}$. Selain itu, tenaga perawat memberikan kontribusi besar terhadap keberhasilan pelayanan kesehatan paripurna kepada klien. Oleh karena itu, penting dilakukan studi untuk mengeksplorasi persepsi perawat tentang dampak akreditasi terhadap mutu pelayanan kesehatan di rumah sakit 7 .

\section{Metode}

Metode yang digunakan adalah penelitian kualitatif dengan desain fenomenologi. Penelitian kualitatif digunakan untuk menggali persepsi perawat berdasarkan pengalaman mereka tentang dampak akreditasi terhadap mutu pelayanan kesehatan.

Penelitian ini dilakukan pada bulan Juni 2020 dengan partisipan berjumlah 53 orang dibagi menjadi tujuh grup. Pemilihan partisipan menggunakan kriteria inklusi dan ekslusi. Kriteria inklusinya adalah kepala ruang (rawat inap, rawat jalan atau rawat khusus) dengan masa jabatan lebih dari lima tahun dan berpendidikan sarjana keperawatan serta aktif sebagai anggota Kelompok Kerja (POKJA) akreditasi. Partisipan dalam penelitian ini berasal dari 4 rumah sakit yaitu $1 \mathrm{RS}$ di wilayah DKI Jakarta, 2 RS di wilayah Sumatera Utara dan 1 RS di wilayah Aceh dengan kriteria Rumah Sakit Umum (RSU), kelas B, sudah terakreditasi paripurna dua kali dengan Standar Akreditasi Versi 2012 dan Standar Nasional Akreditasi Rumah Sakit (SNARS) Edisi 1.

Pengambilan data dilakukan dengan tetap memperhatikan dan menerapkan protokol Kesehatan. Setiap anggota peneliti membagi partisipan ke dalam dua kelompok pertemuan, dengan 6 sampai 8 partisipan per kelompok. Pemilihan kelompok diserahkan kepada partisipan dengan cara memilih salah satu dari dua jadwal pelaksanaan FGD yang ditawarkan oleh peneliti. Penelitian diawali dengan menjelaskan tujuan penelitian, prosedur penelitian, instrumen penelitian serta tata cara menuliskan jawaban pada instrumen, membacakan informed consent penelitian. Selanjutnya peneliti melakukan FGD.

Hasil FGD kemudian disusun dalam bentuk transkrip serta dianalisis dengan menetapkan kategori dan tema. Pada analisis data, dilakukan diskusi antara empat anggota peneliti untuk meningkatkan reliabilitas dalam menyusun kategori dan tema dari hasil FGD. Selanjutnya peneliti melakukan interpretasi dan menarik kesimpulan

Penelitian dilakukan setelah mendapatkan Ethical Clearance dari Komite Etik Penelitian Kesehatan Fakultas Keperawatan Universitas Sumatera Utara dengan nomor 2196/VI/SP/2020 pada 15 Juni 2020 dan surat izin melakukan penelitian dari empat direktur rumah sakit.

\section{Hasil}

Tabel 1 mendeskripsikan 53 partisipan menurut jenis kelamin, usia, dan masa kerja. Jenis kelamin terbanyak perempuan, jabatan terbanyak Kepala Ruang, dan masa kerja terbanyak selama 21-25 tahun.

Tabel 1. Distribusi Partisipan FGD berdasarkan Jenis Kelamin, Usia dan Masa Kerja $(\mathrm{n}=53)$

\begin{tabular}{lcc}
\hline Karakteristik Partisipan & Frekuensi & $\mathbf{\%}$ \\
\hline Jenis Kelamin & & \\
Laki-laki & 10 & 18,86 \\
Perempuan & 43 & 81,14 \\
Usia & 3 & \\
$26-35$ & 35 & 5,60 \\
$36-45$ & 14 & 66,03 \\
$46-55$ & 1 & 26,41 \\
$56-65$ & & \\
Masa Kerja & 3 & 5,96 \\
$6-10$ & 9 & 16,98 \\
$11-15$ & 14 & 26,41 \\
$16-20$ & 17 & 32,07 \\
$21-25$ & 7 & 13,20 \\
$26-30$ & 3 & 5,67 \\
$31-35$ & & \\
\hline
\end{tabular}

Menurut persepsi perawat, akreditasi memiliki dampak positif dan negatif, serta berdampak akreditasi terhadap mutu pelayanan RS (Tabel 2).

Berikut adalah dampak positif akreditasi. Sarana dan prasarana lebih lengkap, seperti yang disampaikan oleh partisipan berikut ini: "Dari segi sarana, lebih lengkap, rumah sakit lebih usaha memenuhi sarana atau infrastruktur yang dibutuhkan oleh ruangan atau setiap unit layanan”. (P2).

Selain kelengkapan sarana dan prasarana, rumah sakit juga menjadi lebih bersih dan nyaman seperti pendapat partisipan berikut ini: "Rumah sakit menjadi lebih bersih dan nyaman, sarana lebih lengkap". ( $\left.\mathrm{P}_{5}\right)$.

Kepatuhan rumah sakit terhadap regulasi yang ada juga meningkat. Berikut adalah kuotasi untuk mengilustrasikan hal tersebut:

"Dalam memberikan pelayanan lebih terarah sesuai dengan Standar Prosedur Operasional [SPO], Kebijakan, Regulasi”. (P38).

"Dapat mengarahkan dalam standar membuat program serta kebijakan.”. (P21).

Peningkatan pengetahuan dan keterampilan serta kompetensi yang harus dimiliki oleh staf rumah sakit. Hal ini dapat diketahui dari pendapat partisipan berikut ini: "Sumber Daya Manusia [SDM] lebih diperhatikan oleh pihak manajemen terutama dalam peningkatan ilmu sesuai dengan kompetensi, banyak untuk dikirim pelatihan, manajemen memenuhi standar-standar yang ada di rumah sakit dalam meningkatkan akreditasi”. (P32).

Sistem pendokumentasian juga menjadi lebih baik. Pendokumentasian dilakukan sesuai standar, seperti pernyataan partisipan berikut ini: "Terlihat dari segi dokumentasi kita lebih rapi, kalau dulu yang penting asal ada saja, yang penting ditulis saja karena tidak ada evaluasi”. (P1). 
Tabel 2. Persepsi Perawat mengenai Dampak Akreditasi terhadap Mutu Pelayanan Rumah Sakit (n=53)

\begin{tabular}{lll}
\hline \multicolumn{1}{c}{ Dampak Positif Akreditasi } & Dampak Negatif Akreditasi & $\begin{array}{c}\text { Dampak Akreditasi Terhadap } \\
\text { Mutu Pelayanan }\end{array}$ \\
\hline $\begin{array}{l}\text { Sarana prasarana menjadi } \\
\text { lebih lengkap }\end{array}$ & Dokumentasi menjadi lebih banyak & $\begin{array}{l}\text { Pelayanan yang diberikan di RS sesuai } \\
\text { standar } \\
\text { Pegulasi-regulasi sesuai } \\
\text { standar dan lebih lengkap }\end{array}$ \\
$\begin{array}{l}\text { Peningkatan pengetahuan mutu dan keselamatan } \\
\text { dan keterampilan staf }\end{array}$ & Beban kerja meningkat & pasien \\
rumah sakit & Tidak melibatkan seluruh staf rumah sakit & \\
$\begin{array}{l}\text { Sistem pendokumen meningkat } \\
\text { menjadi lebih baik }\end{array}$ & & \\
$\begin{array}{l}\text { Peningkatan mutu } \\
\text { pelayanan }\end{array}$ & Membutuhkan biaya yang besar & \\
$\begin{array}{l}\text { Melindungi keselamatan pasien dan staf } \\
\text { Budaya organisasi menjadi lebih baik }\end{array}$ & Rumah sakit tidak mampu menyediakan fasilitas \\
\hline
\end{tabular}

Selain pendokumentasian lebih rapi, mutu pelayanan meningkat. Pelayanan yang diberikan menjadi seragam, sesuai dengan regulasi RS. Hal ini dapat terlihat dari pernyataan partisipan berikut ini:

"Peningkatan mutu pelayanan Rumah Sakit [RS], tercapainya patient safety dan pelayanan semakin cepat". (P46).

"Pelayanan seragam di seluruh rumah sakit”. (P2).

"Pasien merasa puas, ada rasa kepercayaan dengan pelayanan yang diberikan oleh petugas di ruangan.”. ( $\left.\mathrm{P}_{32}\right)$.

"Meningkatkan kepercayaan publik akan RS serta mengurangi komplain pasien.”. (P43).

Akreditasi juga berdampak positif untuk melindungi keselamatan pasien dan staf. Hal ini sesuai dengan pendapat partisipan berikut ini:

"Dalam memberikan pelayanan lebih terarah, lebih prosedural sehingga petugas lebih aman dalam bekerja”. (P33).

"Pelayanan jadi terstandarisasi, RS dan karyawan menjadi terlindungi dari risiko legal hukum kesehatan”. (P18).

"Akreditasi sangat meningkatkan keselamatan pasien dan petugas di rumah sakit”. (P42).

Budaya organisasi menjadi lebih baik serta tata kelola klinis dan manajemen menjadi sesuai standar seperti ungkapan perawat berikut ini:

"Sistem pelayanan di RS tertata dengan baik." (P20).

"Dilihat dari pelayanan lebih terorganisasi dengan baik dalam penyusunan atau struktur dari ruangan, safety pasien menjadi terjamin serta akreditasi dapat meningkatkan kinerja RS, kualitas pelayanan, mendorong perubahan dalam organisasi kesehatan". (P22).

Selain berdampak positif, akreditasi juga memberikan dampak negatif. Dokumentasi menjadi lebih banyak seperti pengisian banyak berkas Rekam Medis (RM). Hal ini sesuai pendapat partisipan berikut ini: "Akreditasi lebih banyak menyita waktu, pengisian formulir RM begitu banyak, juga harus melakukan pengisian monitoring di formulir RM”. (P43).

Beban kerja juga dirasakan perawat menjadi meningkat oleh karena banyak pekerjaan yang harus disiapkan seperti ilustrasi berikut: "Yang saya rasakan, beban kerja RS dan staf jadi bertambah berat dengan adanya akreditasi”. (P47).

Beban kerja yang tinggi tersebut tidak terbagi merata oleh karena akreditasi tidak melibatkan seluruh staf rumah sakit.
Berikut pernyataan partisipan: "Tidak melibatkan semua orang, jadi motivasi itu tidak semua, tidak semua merasa terlibat, ya paling kalau akreditasi ya orang akreditasi saja yang bertanggung jawab untuk itu”. (P1)

Membutuhkan biaya yang besar terkait dengan pengadaan fasilitas, sarana dan prasarana, Pendidikan dan Pelatihan (Diklat) kepada staf, vendor, peserta didik dan lain-lain, sehingga mungkin terdapat realokasi anggaran. Hal ini dapat dilihat dari pernyataan partisipan berikut ini:

"Biaya pengeluaran meningkat untuk fasilitas ruangan". (P11).

"Banyak yang mengeluh jasa lama keluar setelah akreditasi, banyak curiga jasa digunakan untuk proses akreditasi”. ( $\left.\mathrm{P}_{5}\right)$.

Rumah sakit tidak mampu menyediakan sarana dan prasarana yang sesuai standar seperti pendapat partisipan berikut: "Ada hal-hal yang harus dikerjakan yang mengacu kepada standar peralatan tertentu, namun tidak sesuai dengan yang ada di lapangan/klinis". (P31).

Membutuhkan lebih banyak waktu untuk memenuhi standarstandar yang diminta dalam akreditasi. Hal ini sesuai dengan pendapat partisipan berikut ini:

"Terlalu banyak yang harus didokumentasikan di RM pasien sehingga sulit membagi waktu dengan pasien". (P30).

"Menjadi lebih banyak meluangkan waktu di luar waktu kerja”. (P18),

"Saat akreditasi waktu harus rela mundur atau pulang terlambat he..he...”. (P19).

Mutu pelayanan kesehatan menjadi lebih baik, karena dengan akreditasi pelayanan yang diberikan di RS sesuai standar, peningkatan mutu dan keselamatan pasien, serta kepuasan pasien meningkat. Hal ini sesuai dengan pendapat partisipan sebagai berikut ini:

"Mutu pelayanan RS semakin baik, tercapainya keselamatan pasien, pelayanan yang terstandar". (P9).

"Semua menjadi sangat baik, dimana dengan adanya akreditasi kualitas mutu pelayanan di lapangan semakin meningkat dan berjalan sesuai dengan SPO yang berlaku”. (P2O).

"Meningkatkan kepercayaan publik akan RS serta mengurangi komplain pasien”. (P43). 


\section{Pembahasan}

Akreditasi memberikan dampak positif dan dampak negatif. Dampak positif akreditasi diantaranya sarana prasarana menjadi lebih lengkap, regulasi-regulasi sesuai standar dan lebih lengkap, peningkatan pengetahuan dan keterampilan staf rumah sakit, sistem pendokumentasian menjadi lebih baik, peningkatan mutu pelayanan, melindungi keselamatan pasien dan staf serta budaya organisasi menjadi lebih baik. Hal ini sejalan dengan penelitian Mandawati, Fu'adi \& Jaelan yang menyebutkan bahwa dampak positif akreditasi yaitu manajemen membaik, bekerja sesuai standar, keselamatan pasien menjadi prioritas dan fasilitas meningkat 5 . Selain itu, Algahtani, Aldarmahi, Jr \& Shirah menyatakan bahwa akreditasi memiliki dampak positif pada proses dan implementasi perubahan di rumah sakit yang menghasilkan peningkatan dalam pengiriman perawatan pasien dan layanan kesehatan lainnya ${ }^{4}$

Akreditasi mengharuskan rumah sakit membuat regulasiregulasi sesuai standar yang seharusnya dan meminta staf untuk melaksanakan dan patuh terhadap regulasi yang dibuat RS. Firdausi, Dewi \& Susanto menyatakan bahwa akreditasi RS berpengaruh dalam perubahan tingkat kepatuhan staf dalam pengisian surgical safety checklist ${ }^{8}$.

Peningkatan pengetahuan dan keterampilan staf juga menjadi salah satu unsur yang dinilai dalam Standar Akreditasi Rumah Sakit (SNARS) Edisi 1.1. Beberapa standar meminta bukti pelaksanaan pelatihan yang diikuti oleh staf RS seperti pelatihan komunikasi efektif, pelatihan Bantuan Hidup Dasar (BHD) dan pelatihan-pelatihan lainnya9. Hal ini sejalan dengan penelitian Gabriel, dkk yang menyatakan bahwa akreditasi menjadikan budaya organisasi menjadi lebih baik. Proses akreditasi telah membawa perbaikan pada institusi, yang menunjukkan komitmen rumah sakit terhadap kualitas, terutama dalam hal perencanaan kualitas strategis, manajemen kualitas, penggunaan data yang berkaitan dengan kepuasan pasien, keterlibatan staf dan manfaat akreditasi ${ }^{10}$.

Selain berdampak positif, akreditasi juga menimbulkan dampak negatif seperti dokumentasi menjadi lebih banyak, beban kerja meningkat, tidak melibatkan seluruh staf rumah sakit, membutuhkan biaya yang besar, rumah sakit tidak mampu menyediakan fasilitas dan sarana prasarana sesuai standar, membutuhkan waktu yang lebih banyak. Mandawati, Fu'adi \& Jaelan juga menyatakan bahwa dampak negatif akreditasi adalah menyita waktu dan tenaga serta dokumentasi menjadi lebih banyak 5 . Dokumentasi menjadi lebih banyak karena seluruh kegiatan yang dilakukan di RS harus didokumentasikan diantaranya pendokumentasian dalam berkas RM pasien yang meliputi asesmen pasien, tindakan-tindakan medis dan keperawatan, pemberian informasi dan edukasi, pemeriksaan penunjang dan lain sebagainya. Selain itu, pendokumentasian kegiatan pelatihan staf, pendokumentasian kegiatan rapat, pendokumentasian kegiatan penyusunan regulasi di RS dan kegiatan-kegiatan lainnya yang didokumentasikan.

Akreditasi berdampak positif terhadap mutu pelayanan Kesehatan. Pelayanan yang diberikan dirasakan sesuai standar, peningkatan mutu dan keselamatan pasien serta kepuasan pasien menjadi meningkat. Standarisasi terhadap pelayanan yang diberikan oleh sebuah rumah sakit karena akreditasi menyebabkan kualitas asuhan yang diberikan menjadi meningkat. Sebagai bagian dari pelayanan kesehatan yang ada di rumah sakit kualitas pelayanan keperawatan atau asuhan keperawatan yag diberikan juga menjadi meningkat. Hal ini juga sejalan dengan pendapat Andri \& Soewondo yang menyatakan bahwa perawat di rumah sakit yang telah terakreditasi merasakan tingkat yang lebih tinggi terhadap kualitas layanan kesehatan ${ }^{11}$. El-Jardali, dkk menyatakan bahwa menurut perawat Libanon, akreditasi rumah sakit adalah alat yang baik untuk meningkatkan kualitas perawatan ${ }^{12}$.

Mutu pelayanan kesehatan yang baik dapat meningkatkan kepuasan pasien. Pasien puas terhadap pelayanan yang diterima dari suatu rumah sakit. Trisno, Putra \& Purwanza menyatakan bahwa perawat-perawat pada rumah sakit yang telah terakreditasi merasa bahwa kualitas pelayanan kesehatan yang mereka berikan berada pada level lebih tinggi sehingga kepuasan pasien pun meningkat ${ }^{13}$. Semakin baik kualitas layanan kesehatan yang disediakan oleh rumah sakit bagi para pasiennya maka semakin tinggi tingkat kepuasan pasien terhadap rumah sakit ${ }^{14}$. Selain itu, terdapat hubungan yang signifikan antara mutu pelayanan kesehatan dan kepuasan pasien. Semakin tinggi mutu pelayanan maka kepuasan pasien semakin tinggi ${ }^{15}$.

\section{Kesimpulan}

Menurut persepsi perawat, akreditasi memberikan dampak positif dan dampak negatif. Akreditasi memberikan dampak positif terhadap mutu pelayanan Kesehatan, sehingga mutunya dirasakan meningkat. Rumah sakit diharapkan dapat membuat akreditasi sebagai budaya dalam menjaga mutu pelayanan Kesehatan. Untuk peneliti selanjutnya, disarankan agar menggunakan penelitian kuantitatif agar mengetahui pendapat lebih luas, baik dari staf klinis maupun staf non klinis.

\section{Referensi}

1. Undang-Undang Republik Indonesia Nomor 44 Tahun 2009 Tentang Rumah Sakit.

2. Kusbaryanto. Peningkatan Mutu Rumah Sakit dengan Akreditasi. Mutiara Medika. 2010; 10(1): 86-89.

3. Peraturan Menteri Kesehatan Republik Indonesia Nomor 12 Tahun 2020 Akreditasi Rumah Sakit.

4. Algahtani H, Aldarmahi A, Jr JM, dkk. Perception of Hospital Accreditation Among Health Professionals in Saudi Arabia. Ann Saudi Med. 2017 Jul; 37(4): 326-332.

5. Mandawati M, Fu'adi MJ, Jaelan. Dampak Akreditasi Rumah Sakit: Studi Kualitatif Terhadap Perawat di RSUD KRT Setjonegoro Wonosobo. Nurscope. Jurnal Keperawatan dan Pemikiran Ilmiah. 2016; 4(4): 23-29.

6. Undang-Undang Republik Indonesia Nomor 38 Tahun 2014 Tentang Keperawatan.

7. Potter PA, \& Perry AG. Fundamentals of Nursing, Fundamental Keperawatan. Edisi 7, Buku 1 dan 2. Jakarta: EGC. 2009.

8. Firdausi A, Dewi A, Susanto. Pengaruh Akreditasi Rumah Sakit dalam Perubahan Tingkat Kepatuhan Pengisian Surgical Safety Checklist di RS Nur Hidayah. Jurnal Ilmiah Universitas Batanghari Jambi. Februari 2020; 20(1): pp.258-262.

9. Komisi Akreditasi Rumah Sakit (KARS). Standar Nasional Akreditasi Rumah Sakit. Edisi 1.1. Jakarta: Komisi Akreditasi Rumah Sakit (KARS). 2019.

10. Gabriel CS, Bogarin DF, Mikael S, dkk. Brazilian Nurses Perspective on the Impact of Hospital Accreditation. Enfemaria Global. 2017; 49: 408-419. 
11. Andri LP, Soewondo P. Nurses' Perception of Patient Safety Culture in the Hospital Accreditation Era: A Literature Review. The 2nd ICHA; 2020.

12. El-Jardali F, Jamal D, Dimassi H, dkk. The Impact of Hospital Accreditation on Quality of Care: Perception of Lebanese Nurses. International Journal for Quality in Health Care. 2008; 20(5): 363371.

13. Trisno T, Putra AP, Purwanza SW. The Impact of Hospital Accreditation on Nurses' Perceptions of Quality of Care. Jurnal Ners. 2019; 14(3): 402-412.
14. Nugraha KSW, Suryaningsih IB, Paramita C. Pengaruh ElemenElemen Health Care Service Quality (HCSQ) Terhadap Kepuasan Pasien Rumah Sakit Bina Sehat Jember. Jurnal Bisnis dan Manajemen. 2018; 12(3): 313-330.

15. Nurcahyanti E, Setiawan H. Studi Hubungan Antara Mutu Pelayanan Kesehatan dengan Kepuasan Pasien di Unit Pelayanan Rawat Inap Rumah Sakit Umum Daerah Bhakti Dharma Husada Kota Surabaya. Jurnal Manajemen Kesehatan Yayasan RS Dr. Soetomo. 2017; 3(1): 15-30. 